\title{
Oxygen-dependent Lipid Peroxidation during Lung Ischemia
}

Aron B. Fisher, Chandra Dodia, Zhongtuo Tan, Iraimoudi Ayene, and Roderic G. Eckenhoff

Institute For Environmental Medicine, University of Pennsylvania School of Medicine, Philadelphia, Pennsylvania 19104

\begin{abstract}
The effect of alveolar oxygen tension on lung lipid peroxidation during lung ischemia was evaluated by using isolated rat lungs perfused with synthetic medium. After a 5-min equilibration period, global ischemia was produced by discontinuing perfusion while ventilation continued with gas mixtures containing $5 \% \mathrm{CO}_{2}$ and a fixed oxygen concentration between 0 and $95 \%$. Lipid peroxidation was assessed by measurement of tissue thiobarbituric acid-reactive products and conjugated dienes. Control studies (no ischemia) showed no change in parameters of lipid peroxidation during $1 \mathrm{~h}$ of perfusion and ventilation with $20 \%$ or $95 \% \mathrm{O}_{2}$. With $60 \mathrm{~min}$ of ischemia, there was increased lipid peroxidation which varied with oxygen content of the ventilating gas and was markedly inhibited by ventilation with $\mathbf{N}_{2}$. Perfusion with 5-, 8-, 11-, 14-eicosatetraynoic acid indicated that generation of eicosanoids during ischemia accounted for $\sim \mathbf{4 0 - 5 0 \%}$ of lung lipid peroxide production. Changes of $\mathrm{CO}_{2}$ content of the ventilating gas (to alter tissue pH) or of perfusate glucose concentration had no effect on lipid peroxidation during ischemia, but perfusion at $8 \%$ of the normal flow rate prevented lipid peroxidation. Lung dry/wet weight measured after 3 min of reperfusion showed good correlation between lung fluid accumulation and lipid peroxidation. These results indicate that reperfusion is not necessary for lipid peroxidation with ischemic insult of the lung and provide evidence that elevated $\mathrm{PO}_{2}$ during ischemia accelerates the rate of tissue injury. (J. Clin. Invest. 1991. 88:674-679.) Key words: conjugated dienes $\bullet$ hyperoxia $\bullet$ ischemia/reperfusion injury • malondialdehyde $\bullet$ perfused lung
\end{abstract}

\section{Introduction}

Recent studies have provided evidence that tissue damage can occur during the reperfusion period that follows an episode of ischemia (1-4). The mechanism for injury appears to be oxidative damage, in some cases because of activation of the xanthine oxidase enzyme (2) or other reactions for generation of oxidizing chemical species (3). This phenomenon of ischemia/

Results in this work have been presented in part at the 1989 FASEB meeting and the 1989 meeting of the Eastern Section, American Thoracic Society.

Dr. Tan's present address is Deborah Research Institute, Trenton Road, Browns Mills, NJ 08015-1799.

Address reprint requests to Dr. Fisher, Institute for Environmental Medicine, University of Pennsylvania, 1 John Morgan Building, Philadelphia, PA 19104-6068.

Received for publication 6 February 1991 and in revised form 5 April 1991.

J. Clin. Invest.

(C) The American Society for Clinical Investigation, Inc.

0021-9738/91/08/0674/06 \$2.00

Volume 88, August 1991, 674-679 reperfusion injury has been described and studied extensively in the intestine, kidneys, heart, and brain, among other organs (4). In these organs, interruption of perfusion results in both ischemia as well as tissue hypoxia, and it is widely believed that the reintroduction of oxygen to the tissues plays a major role in the production of oxidative injury (1).

Ischemia/reperfusion injury has also been described in the lung, although the metabolic mechanisms have not yet been elucidated (5-10). It is important to note that unlike other organs, ischemia of the lung does not result necessarily in tissue hypoxia. In fact, cessation of pulmonary perfusion to a lung segment, assuming no change in ventilation, might be expected to increase alveolar $\mathrm{PO}_{2}$ and oxygenation of the tissue in that segment. Therefore, reperfusion is not necessary for the "restoration" of tissue oxygenation with lung ischemia. As a corollary, the lung affords a unique opportunity to separate the effects of ischemia and anoxia on tissue function.

In this study, we investigated the effect of alveolar $\mathrm{O}_{2}$ tension during the ischemic period on tissue oxidative damage, i.e., lipid peroxidation assessed by the measurement of thiobarbituric acid-reactive substances (TBARS) ${ }^{1}$ and of conjugated dienes in the lung tissue. The experimental model was the isolated perfused rat lung where the alveolar $\mathrm{Po}_{2}$ could be controlled by manipulation of the ventilating gas and lung ischemia could be produced by a global cessation of perfusion.

\section{Methods}

Sprague-Dawley male rats, CRL:CD (SD) BR (Charles River Breeding Laboratories, Kingston, NY) weighing $180-200 \mathrm{~g}$, were anesthetized with pentobarbital, $50 \mathrm{mg} / \mathrm{kg}$, and prepared for isolated lung perfusion using recirculating perfusate as previously described (11). The trachea was cannulated and lungs were ventilated at $60 \mathrm{cycles} / \mathrm{min}, 2 \mathrm{ml}$ tidal volume, and $2 \mathrm{~cm} \mathrm{H}_{2} \mathrm{O}$ end-expiratory pressure. The thorax was then opened and a cannula was placed in the main pulmonary artery through the transected heart. The lungs were initially cleared of blood by gravity flow of perfusate ( $25 \mathrm{~cm} \mathrm{H}_{2} \mathrm{O}$ pressure), carefully removed from the thorax, trimmed of cardiac and other nonpulmonary tissue, and then transferred to the water-jacketed perfusion chamber maintained at $37^{\circ} \mathrm{C}$. There was no interruption of ventilation during this transfer process and interruption of lung perfusion was $<5 \mathrm{~s}$. Perfusion into the pulmonary artery was maintained by a peristaltic pump at a constant flow rate of $12 \mathrm{ml} / \mathrm{min}$; the perfusate dripped from the transected left atrium and was collected and recirculated. The total volume of recirculating perfusate was $40 \mathrm{ml}$. Ventilation pressure was continuously monitored with a pressure transducer (PM 131TC, Statham Instruments, Oxnard, CA) and a direct writing oscillograph (Gould, Inc., Cleveland, $\mathrm{OH}$ ).

The control gas for lung ventilation was $5 \% \mathrm{CO}_{2}$ in air; all ventilation gases contained $5 \% \mathrm{CO}_{2}$ unless otherwise stated. Perfusate was Krebs-Ringer bicarbonate buffer (pH 7.4) containing $10 \mathrm{mM}$ glucose, $5 \%(\mathrm{wt} / \mathrm{vol}$ ) fatty acid-free bovine serum albumin (Boehringer-Mannheim Biochemicals, Indianapolis, IN) and pre-equilibrated with the same gas mixture subsequently used for lung ventilation.

1. Abbreviations used in this paper: ETYA, 5-,8-,11-,14-eicosatetraynoic acid; TBARS, thiobarbituric acid-reactive substance. 
Lungs were perfused for an initial 5-min equilibration period. Perfusion was then discontinued by turning off the pump motor while ventilation continued. Each experiment used one of the following for the ventilating gas during ischemia: $0,5 \%, 20 \%, 50 \%$, or $95 \% \mathrm{O}_{2}$ plus $5 \% \mathrm{CO}_{2}$, balance $\mathrm{N}_{2}$. Premixed gases were obtained from Airco Inc., Philadelphia, PA. After an ischemic period of 15,30 , or $60 \mathrm{~min}$, perfusion was restarted at the same flow rate and continued for 3 min while ventilating with $95 \% \mathrm{O}_{2}$. The brief reperfusion period was utilized to permit evaluation of lung damage by measurement of fluid accumulation.

At the end of 3-min reperfusion, the lungs were rapidly frozen by clamping with aluminum tongs precooled in liquid $\mathrm{N}_{2}$. A portion of the frozen lung was weighed (wet weight) and then dried in an oven at $60^{\circ}$ to constant weight (dry weight). The remainder of lung tissue was immediately homogenized under $\mathrm{N}_{2}$ in ice-cold saline (1:10, tissue/medium) containing $0.2 \%$ butylated hydroxytoluene using a stainless steel micro jar attached to a Waring Blendor (Thomas Scientific, Philadelphia, PA) at maximum speed for $2 \mathrm{~min}$. The homogenate was frozen at $-80^{\circ}$ under $\mathrm{N}_{2}$ and was assayed within $3 \mathrm{~d}$. TBARS were assayed in the homogenate after extraction with boiling trichloroacetic acid by the method of Buege and Aust (12) and expressed as picomoles per milligram protein (12). A portion of the lung homogenate was extracted by the method of Bligh and Dyer (13) and used to assay for conjugated dienes as described by Thom (14). Briefly, the organic fraction was removed by evaporation under $\mathrm{N}_{2}$ and the lipid residue was dissolved in chloroform/methanol $(1: 6, \mathrm{vol} / \mathrm{vol})$ for measurement of absorbance at $233 \mathrm{~nm}$ using a spectrophotometer (model U-3210, Hitachi Instruments Inc., Danbury, CT). Units for conjugated dienes are expressed as millioptical density units per milligram of protein. To measure lung ATP content, a portion of the lung homogenate was extracted with cold ethanolic perchloric acid and assayed enzymatically using hexokinase and glucose-6-phosphate dehydrogenase (15). Protein content of the lung homogenate and extracts was measured using the Coomassie Blue reaction (16).

Results are generally expressed as mean $\pm \mathrm{SE}$. Data were analyzed statistically by factorial analysis of variance (ANOVA) for the effect of increasing $\mathrm{O}_{2}$ or by ANOVA followed by Dunnett's test for other comparisons (17). The level of statistical significance was taken as $P<0.05$.

\section{Results}

Lungs evaluated immediately after the equilibration period before production of ischemia showed values for tissue TBARS, ATP, and dry/wet weight (Table I) similar to previously published values for perfused lungs $(15,18)$. Control lungs which were perfused for an additional $60 \mathrm{~min}$ (no ischemia) and ventilated with either $20 \%$ or $95 \% \mathrm{O}_{2}$ showed no significant change in tissue TBARS, conjugated dienes, ATP, or dry/wet weight (Table I).

TBARS in lung homogenate increased significantly with ischemia and showed a dependence on time of ischemia and alveolar $\mathrm{O}_{2}$ concentration (Fig. 1). With ischemia for $60 \mathrm{~min}$,

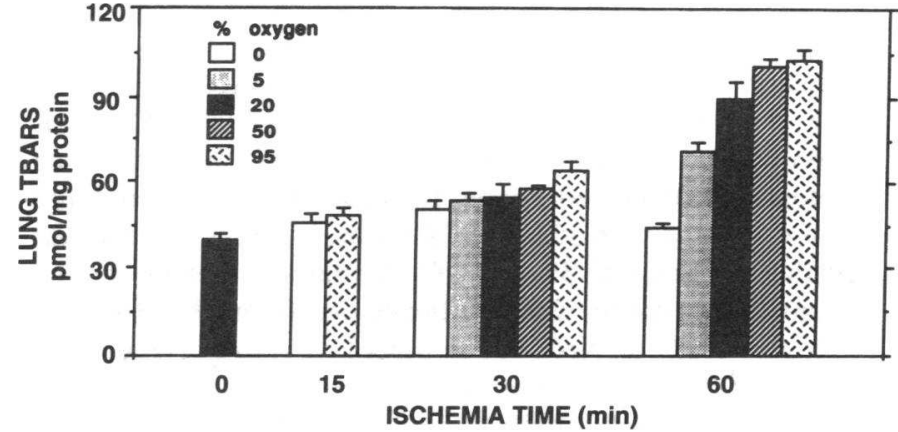

Figure 1. The effect of oxygen content of the ventilating gas on lung TBARS. Isolated rat lungs were ischemic for 15,30 , or 60 min during ventilation with gas of varying oxygen concentrations as indicated. All gas mixtures for ventilation contained in addition $5 \% \mathrm{CO}_{2}$, balance $\mathrm{N}_{2}$. The zero ischemia time is the same value as in Table I for 0 -min perfusion. Results are mean \pm SE for $n=4-8$. The increase in TBARS as a function of $\mathrm{O}_{2}$ was statistically significant $(P<0.05)$ (see text) for 60 -min ischemia.

TBARS increased by $162 \%$ above the control (no ischemia) lungs during ventilation with $20 \%$ oxygen. Ventilation with $\mathrm{N}_{2}$ during ischemia effectively abolished the increase of lung TBARS, whereas ventilation with $5 \% \mathrm{O}_{2}$ resulted in a tissue TBARS content between the $\mathrm{N}_{2}$ and $20 \% \mathrm{O}_{2}$ values. There was essentially no change in tissue TBARS between $50 \%$ and $95 \%$ alveolar $\mathrm{O}_{2}$, suggesting a plateau of the $\mathrm{O}_{2}$ effect. The increase of lung TBARS as a function of $\mathrm{O}_{2}$ concentration was statistically significant $(F=43.08 ; \mathrm{df}=4 ; P<0.05)$ by ANOVA using unweighted means analysis for unequal $n(17)$. With $30 \mathrm{~min}$ of ischemia, TBARS showed a similar pattern as with $60 \mathrm{~min}$ although a lesser change was observed at each $\mathrm{O}_{2}$ concentration and the $\mathrm{O}_{2}$ effect was not statistically significant (Fig. 1). A small elevation of TBARS with $15 \mathrm{~min}$ of ischemia (studied with $\mathrm{N}_{2}$ and $95 \% \mathrm{O}_{2}$ only) was also not significantly different than control values (Fig. 1).

We determined whether the 3-min reperfusion period following ischemia was necessary for the generation of lipid peroxidation products. Lungs were ventilated with $20 \% \mathrm{O}_{2}$ during 60-min ischemia and assayed for TBARS without reperfusion. Lung TBARS were $84.0 \pm 6.6 \mathrm{pmol} / \mathrm{mg}$ protein $(n=4)$, not significantly different from lungs that had been ventilated with $20 \% \mathrm{O}_{2}$ for $60 \mathrm{~min}$ and reperfused for $3 \mathrm{~min}$ (Fig. 1 and Table II). Therefore, the increase in tissue TBARS occurred during the ischemic period and not during the brief reperfusion.

Conjugated dienes were evaluated as a separate index of tissue lipid peroxidation and gave results essentially parallel to

Table I. Control Studies for Isolated Perfused Rat Lungs

\begin{tabular}{|c|c|c|c|c|c|}
\hline $\begin{array}{l}\text { Duration of } \\
\text { perfusion }\end{array}$ & $\begin{array}{c}\mathrm{O}_{2} \text { in } \\
\text { ventilating gas }\end{array}$ & $\begin{array}{c}\text { Tissue } \\
\text { TBARS }\end{array}$ & $\begin{array}{l}\text { Conjugated } \\
\text { dienes }\end{array}$ & ATP & $\begin{array}{c}\text { Dry/wet } \\
\text { wt }\end{array}$ \\
\hline $\min$ & $\% *$ & $\mathrm{pmol} / \mathrm{mg}$ protein & $m O D / m g$ protein & $\mu \mathrm{mol} / \mathrm{g} d r y \mathrm{wt}$ & \\
\hline $0^{\ddagger}$ & 20 & $38.4 \pm 1.8$ & $4.9 \pm 0.3$ & $9.3 \pm 0.6$ & $0.180 \pm 0.001$ \\
\hline 60 & 20 & $33.6 \pm 1.8$ & $4.6 \pm 0.07$ & $9.0 \pm 0.2$ & $0.181 \pm 0.002$ \\
\hline 60 & 95 & $36.0 \pm 1.8$ & $5.0 \pm 0.48$ & ND & $0.180 \pm 0.002$ \\
\hline
\end{tabular}

Results are mean \pm SE for $n=4-7 . \mathrm{ND}$, not determined. $*$ Ventilation gas contained in addition $5 \% \mathrm{CO}_{2}$, balance $\mathrm{N}_{2}$. ${ }^{\ddagger} \mathrm{Cleared}$ of blood only. 
that observed for TBARS (Fig. 2), although no plateau value was observed. For all data, there was a statistically significant correlation between conjugated dienes and TBARS $(r=0.78 ; n$ $=58 ; P<0.001)$. With ischemia for $60 \mathrm{~min}$ and $20 \% \mathrm{O}_{2}$ ventilation, the tissue conjugated dienes increased $65 \%$. The tissue content of conjugated dienes increased further when lungs were ventilated with $50 \%$ or $95 \% \mathrm{O}_{2}$ during ischemia and was significantly less with $5 \%$ or $0 \% \mathrm{O}_{2}$ ventilation. The effect of $\mathrm{O}_{2}$ on conjugated dienes was statistically significant $(F=16.25$; df $=4 ; P<0.05)$ by ANOVA as described above. There was a similar $\mathrm{O}_{2}$ dependence during 30 -min ischemia but the elevations were relatively small and were not statistically significant (Fig. 2). With 15-min ischemia, the increase in tissue conjugated dienes was also not statistically significant (Fig. 2).

In order to determine the role of eicosanoid metabolism in the generation of lung lipid peroxidation products, we evaluated the effect of indomethacin on production of TBARS and conjugated dienes. Anesthetized rats were given $20 \mathrm{mg}$ of indomethacin into the dorsal vein of the penis $10 \mathrm{~min}$ before removal of lungs which were then perfused at $12 \mathrm{ml} / \mathrm{min}$ with medium containing $30 \mathrm{mM}$ indomethacin for 63 min (perfused), or for a 5-min equilibration period before cessation of perfusion (ischemic). Ischemia was continued for $60 \mathrm{~min}$, during which lungs were ventilated with $5 \% \mathrm{CO}_{2}$ in air, followed by reperfusion at $12 \mathrm{ml} / \mathrm{min}$ for $3 \mathrm{~min}$. This regimen for indomethacin treatment essentially abolished production of thromboxane $\mathrm{B}_{2}$ assayed in the lung homogenate and perfusion medium with a radioimmunoassay kit (Amersham Corp., Arlington Heights, IL) (data not shown) consistent with previous results of others with perfused rabbit lungs (19). Ischemia produced a significant increase in TBARS in ischemic lungs even in the presence of indomethacin. Although TBARS after ischemia were $15 \%$ less in indomethacin treated lungs compared with control ischemic lungs (no indomethacin) this effect was not statistically significant (Table II). Values for conjugated dienes in the ischemic lung treated with indomethacin $(6.8 \pm 0.7 \mathrm{mOD} / \mathrm{mg}$ protein) indicated a similar effect. Additional experiments $(n=4)$ utilized $100 \mu \mathrm{M}$ 5-, 8-, 11-, 14-eicosatetraynoic acid (ETYA, BIOMOL Research Laboratories, Inc., Plymouth Meeting, PA), an inhibitor of both lipoxygenase and cyclooxygenase pathways (20), added to the perfusate during the equilibration period. Lungs were ventilated with $5 \%$

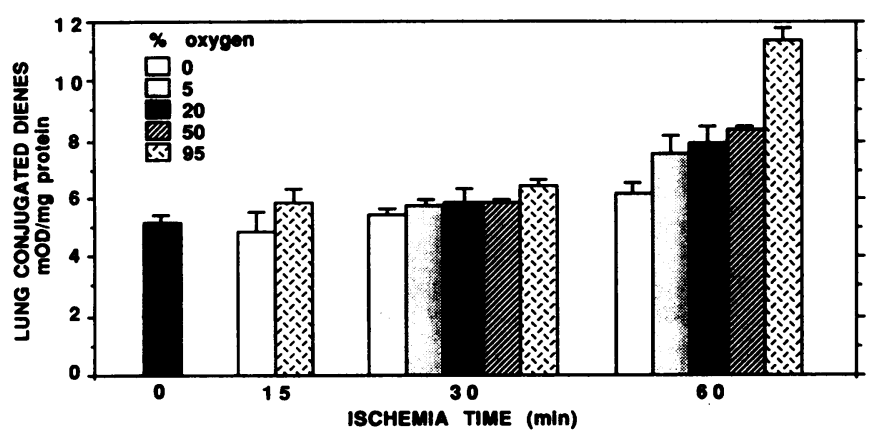

Figure 2. Effect of oxygen content of the ventilating gas on tissue conjugated dienes during lung ischemia for 15,30 , or $60 \mathrm{~min}$. Experimental conditions and presentation of data are indicated in the legend to Fig. 1. The increase in conjugated dienes as a function of $\mathrm{O}_{2}$ was statistically significant $(P<0.05)$ (see text) for 60 -min ischemia.
Table II. Effect of Eicosanoid Metabolism Inhibitors on Generation of TBARS by the Isolated Rat Lung

\begin{tabular}{lccc}
\hline & \multicolumn{3}{c}{ TBARS } \\
\cline { 2 - 4 } & Control* $^{*}$ & Indomethacin & ETYA \\
\hline & \multicolumn{3}{c}{ pmol/mg protein } \\
Perfused & $33.6 \pm 1.8$ & $29.1 \pm 1.7$ & $35.7 \pm 2.2$ \\
Ischemic & $87.9 \pm 5.7^{\ddagger}$ & $75.0 \pm 4.8^{\ddagger}$ & $64.8 \pm 6.0^{\ddagger 5}$ \\
Mean change & 54.3 & 45.9 & 29.1 \\
\hline
\end{tabular}

All lungs were ventilated with $20 \% \mathrm{O}_{2} / 5 \% \mathrm{CO}_{2}$ /balance $\mathrm{N}_{2}$. Control lungs were perfused at $12 \mathrm{ml} / \mathrm{min}$ for $63 \mathrm{~min}$. Experimental lungs were ischemic for $60 \mathrm{~min}$ followed by reperfusion for $3 \mathrm{~min}$.

Results are mean \pm SE for $n=4$. See text for concentrations of inhibitors.

* Results for perfused from Table I and for ischemic from Fig. 1.

$¥ P<0.05$ vs. perfused.

${ }^{8} P<0.05$ vs. control.

$\mathrm{CO}_{2}$ in air during $60 \mathrm{~min}$ of ischemia. TBARS were significantly increased by ischemia comparing perfused and ischemic ETYA-treated lungs (Table II). However, lung TBARS after 60 min of ischemia in the presence of ETYA was significantly decreased by $46 \%$ compared with control (minus ETYA) (Table II). There was no significant effect of either eicosanoid inhibitor on TBARS in normally perfused lungs (Table II). Therefore, total eicosanoid metabolism apparently accounted for nearly half of lung lipid peroxidation products due to ischemia. The greater effect of ETYA compared with indomethacin suggests that the major component of eicosanoid-related lipid peroxidation was due to lipoxygenase activity.

The normal lung has a very large blood flow in relation to tissue mass, far in excess of that required for its metabolic needs. In order to assess the role of perfusion flow rate for oxidative injury, lungs were perfused at $1 \mathrm{ml} / \mathrm{min}$ (vs. the standard $12 \mathrm{ml} / \mathrm{min}$ ) for $60 \mathrm{~min}$ and ventilated with $20 \% \mathrm{O}_{2}$. Lung TBARS were $42.3 \pm 1.8 \mathrm{pmol} / \mathrm{mg}$ protein $(n=4)$ and conjugated dienes were $5.1 \pm 0.6 \mathrm{mOD} / \mathrm{mg}$ protein, results not significantly different from control values. This indicates that a relatively low level of lung perfusion was sufficient to prevent lipid peroxidation.

In order to evaluate the role of possible $\mathrm{pH}$ change during the ischemic period, the ischemic lungs were ventilated with gas containing no $\mathrm{CO}_{2}$ (alkalosis) or $80 \% \mathrm{CO}_{2}$ (acidosis) in $20 \%$ $\mathrm{O}_{2}$. Equilibrium values for perfusate $\mathrm{pH}$ under these conditions were 7.8 and 6.6 , respectively, compared with the control value of 7.4. Although TBARS were increased under both acidotic and alkalotic conditions (Table III), the difference from usual $\mathrm{pH}$ was not statistically significant. Ventilation with $80 \%$ $\mathrm{CO}_{2}$ during normal perfusion $(15 \mathrm{ml} / \mathrm{min})$ also did not affect lung TBARS (Table III compared with Table I).

Lung ATP content was significantly decreased during ventilation with $\mathrm{N}_{2}$ but was maintained (no significant change from the control value of $9.0 \pm 0.2$ ) during ischemia when lungs were ventilated with $5 \%$ or $20 \% \mathrm{O}_{2}$ (Table IV). This suggests that availability of metabolizable substrate was not limiting for ATP synthesis during the ischemic period. In order to test further the possibility that lipid peroxidation resulted from substrate depletion in the absence of perfusion flow, lungs were 
Table III. Effect of $\mathrm{CO}_{2}$ in Ventilating Gas on Lung TBARS during Ischemia

\begin{tabular}{rlc}
\hline $\mathrm{CO}_{2}^{*}$ & \multicolumn{1}{c}{ Condition } & TBARS \\
\hline$\%$ & & pmol/mg protein \\
5 & Normal pH & $84.0 \pm 6.6$ \\
0 & Alkalosis & $94.5 \pm 3.3$ \\
80 & Acidosis & $99.3 \pm 3.0$ \\
80 & No ischemia, acidosis & $37.2 \pm 0.3^{\ddagger}$
\end{tabular}

TBARS were measured after $60 \mathrm{~min}$ of ischemia, without reperfusion. Values are mean \pm SE for $n=4$.

* $\mathrm{CO}_{2}$ in the ventilating gas plus $20 \% \mathrm{O}_{2}$ with the balance $\mathrm{N}_{2}$.

${ }^{\ddagger} \mathrm{P}<0.05$ vs. all other conditions.

perfused with medium containing $20 \mathrm{mM}$ glucose (twice the usual concentration) during the equilibration period and then subjected to $60 \mathrm{~min}$ ischemia with $20 \% \mathrm{O}_{2}$ ventilation. In additional experiments, lungs were perfused at $1 \mathrm{ml} / \mathrm{min}$ with medium containing zero glucose and ventilated with $20 \% \mathrm{O}_{2}$. Lung TBARS under these two conditions $(n=4)$ were $92.4 \pm 8.1$ and $38.7 \pm 3.6 \mathrm{pmol} / \mathrm{mg}$ protein, respectively, which is not significantly different from values with the corresponding standard $(10 \mathrm{mM})$ glucose concentration. Therefore, glucose depletion during ischemia did not appear to play a role in promoting lung lipid peroxidation.

There was no evidence of alveolar edema in any of these experiments by gross inspection of lungs. Ventilation pressure for the lungs at constant tidal volume remained constant under all experimental conditions of variable ischemia duration and oxygenation and did not change significantly during the 3-min reperfusion period (data not shown). Tissue dry/wet weight measured at the end of the reperfusion period was unchanged during 60 min of ischemia when lungs were ventilated with $\mathrm{N}_{2}$ (Table V). However, lungs ventilated with increased concentrations of $\mathrm{O}_{2}$ showed an oxygen- and time-dependent decrease in dry/wet weight indicating an accumulation of fluid (Table V), presumably occurring during the 3-min reperfusion period. The effect of $\mathrm{O}_{2}$ was statistically significant $(F=8.93$; df $=4 ; P$ $<0.05$ ) for the 60 -min ischemia values. There was a statistically significant correlation of lung dry/wet weight with

Table IV. Effect of $\mathrm{O}_{2}$ during Ischemia on Lung ATP Content

\begin{tabular}{rll}
\hline & \multicolumn{2}{c}{ ATP } \\
\cline { 2 - 3 } $\mathrm{O}_{2}^{*}$ & 30 -min ischemia & 60 -min ischemia \\
\hline$\%$ & \multicolumn{3}{c}{$\mu m o l / g d r y w t$} \\
0 & $5.2 \pm 0.1^{\ddagger}$ & $4.1 \pm 0.06^{\ddagger 5}$ \\
5 & $8.2 \pm 0.2$ & $8.1 \pm 0.5$ \\
20 & $8.4 \pm 0.1$ & $8.2 \pm 0.1$ \\
& &
\end{tabular}

Values are mean \pm SE for $n=4$ for each condition. ATP was measured after $3 \mathrm{~min}$ of reperfusion.

${ }^{*} \mathrm{O}_{2}$ content of the ventilating gas plus $5 \% \mathrm{CO}_{2}$, balance $\mathrm{N}_{2}$.

${ }^{\ddagger} P<0.05$ vs. other $\% \mathrm{O}_{2}$ values at the same time point.

${ }^{8} P<0.05$ vs. corresponding 30 -min value.
Table V. Effect of $\mathrm{O}_{2}$ during Ischemia on Lung Dry/Wet Weight

\begin{tabular}{cccc}
\hline \multicolumn{4}{c}{ Dry weight $\times 100 /$ wet weight } \\
\hline \multicolumn{3}{c}{ Ischemia time $\min$} \\
\cline { 2 - 4 } $\mathrm{O}^{*}$ & 15 & 30 & $60^{\ddagger}$ \\
\hline$\%$ & & $g \times 100 / g$ & \\
0 & $18.5 \pm 0.6$ & $18.0 \pm 0.4$ & $18.2 \pm 0.3$ \\
5 & ND & $17.8 \pm 0.4$ & $17.2 \pm 0.4$ \\
20 & ND & $17.6 \pm 0.7$ & $15.4 \pm 0.1$ \\
50 & ND & $17.4 \pm 0.2$ & $15.2 \pm 0.1$ \\
95 & $19.0 \pm 0.5$ & $17.2 \pm 0.4$ & $14.8 \pm 0.2$
\end{tabular}

Values are mean \pm SE for $n=4-8$ for each condition

Values were obtained at the end of $3 \mathrm{~min}$ of reperfusion.

ND, not determined.

* $\mathrm{O}_{2}$ content of the ventilating gas plus $5 \% \mathrm{CO}_{2}$, balance $\mathrm{N}_{2}$.

${ }^{\ddagger} P<0.05$ for the effect of $\mathrm{O}_{2}$.

TBARS $(r=-0.76 ; n=58 ; P<0.001)$ and with conjugated dienes $(r=-0.62 ; n=58 ; P<0.001)$.

\section{Discussion}

These studies used the isolated rat lung model to investigate oxidative injury during lung ischemia. Ischemia was produced by discontinuing perfusion to the lungs while ventilation continued in order to maintain and vary tissue oxygenation. Consequently, we were able to evaluate the role of $\mathrm{O}_{2}$ tension during lung ischemia in the production of lung injury, without invoking potential systemic influences as might occur if the experiment were performed in situ. These isolated lungs were perfused with artificial media so that blood components and cellular elements did not contribute to the tissue changes seen with ischemia.

Lipid peroxidation was evaluated by the measurement of lung tissue TBARS and conjugated dienes, components that are generated at opposite ends of the lipid peroxidation cascade. Thus, conjugated dienes represent the initial phase of oxidative attack on a complex lipid whereas TBARS represent in large part the final stage related to the decomposition of peroxidized lipids (12). The close correspondence of two different parameters in response to experimental manipulation increases the level of confidence in their use as indices of tissue lipid peroxidation (20). The increase in lipid peroxidation products could represent either the generation of eicosanoids from arachidonic acid or the less specific peroxidation of membrane or other tissue lipids. Based on studies with inhibitors of the cyclooxygenase and lipoxygenase pathways, $\sim 40-50 \%$ of the increase in lipid peroxidation products in this study was related to activation of eicosanoid metabolism by ischemia, compatible with previous reports of increased eicosanoid production during oxidative injury (19). Conversely, more than half of the lipid peroxidation products presumably arose from attack on tissue lipids.

The results of the present study indicate that peroxidation of lung lipid occurs during a period of lung ischemia and that a reperfusion phase is not necessary for oxidative lung injury. 
This result is compatible with a recent study of rat intestine using salicylate as a radical trap which indicated increased production of hydroxyl radicals during ischemia (21). The source of $\mathrm{O}_{2}$ for radical production in the latter study was not determined but presumably represents residual tissue $\mathrm{O}_{2}$ and diffusion from the environment. In the present study, peroxidation increased with increasing $\mathrm{O}_{2}$ in the ventilating gas during ischemia and was significantly inhibited when lungs were ventilated with $\mathrm{N}_{2}$. Although there was a slight increase in peroxidation products at $15 \mathrm{~min}$ of ischemia and a further increase at 30 min, the change from control was not statistically significant until $60 \mathrm{~min}$ of ischemia. We interpret these results to indicate that lipid peroxidation is initiated during lung ischemia and that the presence of $\mathrm{O}_{2}$ is required for the propagation of the chain reaction resulting in the generation of peroxidized lipid products. These results are compatible with the hypothesis put forth for other organs that reperfusion provides $\mathrm{O}_{2}$ for the lipid peroxidation that had been initiated during tissue ischemia (1). Elevated $\mathrm{O}_{2}$ during reperfusion has been shown to result in increased brain injury (22) and increased generation of TBARS in tissue slices of rat liver and kidney (23).

Although this study has not specifically identified the initiating events during lung ischemia that result in lipid peroxidation, we have obtained evidence related to several possibilities. First, perfusate neutrophils were not present and therefore were not required for the ischemic injury, compatible with previous studies of ischemia-reperfusion lung injury (10). Although these experiments could not exclude an effect of marginated neutrophils in lungs, PMN were not observed in electron micrographs from ischemic lungs (results not shown). Further, evaluation of similar perfused lungs for isolation of cells by enzymatic digestion indicates a minimal polymorphonuclear leukocyte population (24), suggesting that marginated neutrophils are probably not involved. The prevention of lipid peroxidation when lungs were perfused at $1 \mathrm{ml} / \mathrm{min}$, or $\sim 8 \%$ of the control rate of lung perfusion, suggests that a pulmonary perfusate factor inhibited the initiation stage. Possibilities for the perfusate factor include the provision of substrate or the removal of metabolites, such as $\mathrm{H}^{+}$. We were not able to prevent lipid peroxidation by alkalosis, reproduce it through acidosis produced by ventilation with high $\mathrm{CO}_{2}$ or to alter the effect by manipulation of perfusate glucose. Thus, the precise initiating factors for lipid peroxidation during total lung ischemia remain to be determined.

The rat lung model in the present studies relied on cessation of perfusion to produce global ischemia while ventilation continued. This model may have relevance for the in situ lung in which there is acute obstruction of blood flow (e.g., pulmonary embolism). As with the present rat model, ventilation should be initially preserved to a lung segment with acutely obstructed perfusion. In the rat model, ventilation with $\mathrm{N}_{2}$ protected the lungs against lipid peroxidation during lung ischemia and prevented the accumulation of fluid during a brief $(3 \mathrm{~min})$ reperfusion period. These results are consistent with our previous physiologic and morphologic observations in intact dogs that ischemic lungs ventilated with $\mathrm{N}_{2}$ (plus $5 \% \mathrm{CO}_{2}$ ) did not show alterations of lung function following reperfusion (25). Further, Koyama et al. (8) showed with isolated canine lung lobes that $\mathrm{N}_{2}$ ventilation during ischemia prevented lobar edema during reperfusion. The results suggest that the absence of $\mathrm{O}_{2}$ protects lung tissue from ischemic damage and, conversely, ventilation of lungs with enriched $\mathrm{O}_{2}$ mixtures during a period of total vascular occlusion may promote tissue oxidative damage. The implications for therapy of pulmonary embolism or other lung vascular insult is to maintain the lowest possible inspired $\mathrm{O}_{2}$ compatible with oxygenation of the arterial blood.

The present results also have relevance for our understanding of pulmonary oxygen toxicity. The rat, which has been studied extensively for hyperoxic injury, demonstrates changes in lung metabolic function after $\sim 24 \mathrm{~h}$ of breathing 1 atmospheres absolute $\mathrm{O}_{2}(26,27)$ with progressive pulmonary changes culminating in death at about $72 \mathrm{~h}(28)$. The present results provide evidence for oxidative injury by $\mathrm{O}_{2}$ within a relatively short time frame (30-60 $\mathrm{min})$ in the abnormal lung. These data indicate that even normal levels of alveolar oxygen may result in tissue oxidative damage under circumstances of tissue ischemia and raise the possibility that alterations of perfusion during $\mathrm{O}_{2}$ exposure may increase susceptibility to lipid peroxidation.

\section{Acknowledgments}

We thank Dr. Stephen Thom for advice concerning assays for lipid peroxidation and Ms. Eleanor Hopkin for statistical analysis.

Support was provided by grant RO-1-HL41939 from the National Institutes of Health. Dr. Z. Tan was a Fellow of the Will Rogers Foundation, White Plains, NY

\section{References}

1. McCord, J. M. 1985. Oxygen-derived free radicals in postischemic tissue injury. N. Engl. J. Med. 312:159-163.

2. Granger, D. N., J. M. McCord, D. A. Parks, and M. E. Hollwarth. 1986 Xanthine oxidase inhibitors attenuate ischemia-induced vascular permeability changes in the cat intestine. Gastroenterology. 90:80-84.

3. Halliwell, B. 1987. Oxidants and human disease: some new concepts. $F A$ SEB (Fed. Am. Soc. Exp. Biol.) J. 1:358-364.

4. Cross, C. E., B. Halliwell, E. T. Borish, W. A. Pryor, B. N. Ames, R. L. Saul, J. M. McCord, and D. Harman. 1987. Oxygen radicals and human disease. Ann. Intern. Med. 107:526-545.

5. Barie, P. S., T. S. Hakim, and A. B. Malik. 1981. Effect of pulmonary artery occlusion and reperfusion on extravascular fluid accumulation. J. Appl. Physiol. 50:102-106.

6. Bishop, M. J., E. S. Boatman, T. D. Ivey, J. P. Jordan, and F. W. Cheyney. 1986. Reperfusion of ischemic dog lung results in fever, leukopenia and lung edema. Am. Rev. Respir. Dis. 134:752-756.

7. Bishop, M. J., E. Y. Chi, and F. W. Cheney, Jr. 1987. Lung reperfusion in dogs causes bilateral lung injury. J. Appl. Physiol. 63:942-950.

8. Koyama, I., T. J. K. Toung, M. C. Rogers, G. H. Gurtner, and R. J. Traystman. 1987. $\mathrm{O}_{2}$ radicals mediate reperfusion lung injury in ischemic $\mathrm{O}_{2}$ ventilated canine pulmonary lobe. J. Appl. Physiol. 63:111-115.

9. Kennedy, T. P., N. V. Rao, C. Hopkins, L. Pennington, E. Tolley, and J. R. Hoidal. 1989. Role of reactive oxygen species in reperfusion injury of the rabbit lung. J. Clin. Invest. 83:1326-1335.

10. Deeb, G. M., C. M. Grum, M. J. Lynch, T. P. Guynn, K. P. Gallagher, A. G. Ljungman, S. F. Bolling, and M. L. Morganroth. 1990. Neutrophils are not necessary for induction of ischemia-reperfusion lung injury. J. Appl. Physiol. 68:374-381.

11. Fisher, A. B., C. Dodia, and J. Linask. 1980. Perfusate composition and edema formation in isolated rat lungs. Exp. Lung Res. 1:13-22.

12. Buege, J. A., and S. D. Aust. 1978. Microsomal lipid peroxidation. Methods Enzymol. 52:302-310.

13. Bligh, E. B., and W. J. Dyer. 1959. A rapid method of total lipid extraction and purification. Can. J. Biochem. Physiol. 37:911-917.

14. Thom, S. R. 1990. Antagonism of carbon monoxide-mediated brain lipid peroxidation by hyperbaric oxygen. Toxicol. Appl. Pharmacol. 105:340-344.

15. Bassett, D. J. P., and A. B. Fisher. 1976. Metabolic response to carbon monoxide by isolated lungs. Am. J. Physiol. 230:658-663.

16. Bradford, M. M. 1976. A rapid and sensitive method for quantitation of microgram quantities of proteins utilizing the principle of protein dye binding. Anal. Biochem. 72:248-254. 
17. Winer, B. J. 1971. Statistical Principles in Experimental Design. 2nd edition. McGraw-Hill Book Co., Inc., New York. 309-335 and 384-388.

18. Petruska, J. M., S. H. Y. Wong, F. W. Sunderman, Jr., and B. T. Mossman. 1990. Detection of lipid peroxidation in lung and in bronchoalveolar lavage cells and fluid. Free Radical Biol. Med. 9:51-58.

19. Farrukh, I. S., J. R. Michael, S. R. Peters, A. M. Sciuto, N. F. Adkinson, Jr., H. S. Freeland, A. Paky, E. W. Spannhake, W. R. Summer, and G. H. Gurtner. 1988. The role of cyclooxygenase and lipoxygenase mediators in oxidant-induced lung injury. Am. Rev. Respir. Dis. 137:1343-1349.

20. Smith, C. V., and R. E. Anderson. 1987. Methods for determination of lipid peroxidation in biological samples. Free Radical Biol. Med. 3:341-344.

21. Udassin, R., I. Ariel, Y. Haskel, N. Kitrossky, and M. Chevion. 1991. Salicylate as an in vivo free radical trap: studies on ischemic insult to the rat intestine. Free Radical Biol. Med. 10:1-6.

22. Mickel, H. S., Y. N. Vaishnav, O. Kempski, D. von Lubitz, J. F. Weiss, G.
Feurestein. 1987. Breathing $100 \%$ oxygen after global brain ischemia results in increased lipid peroxidation and increased mortality. Stroke. 18:426-430.

23. Salaris, S. C., and C. F. Babbs. 1989. Effect of oxygen concentration on the formation of malondialdehyde-like material in a model of tissue ischemia and reoxygenation. Free Radical Biol. Med. 7:603-609.

24. Fisher, A. B., L. Furia, and H. Berman. 1980. Metabolism of rat granular pneumocytes isolated in primary culture. J. Appl. Physiol. 49:743-750.

25. Fisher, A. B., R. W. Hyde, and J. S. Reif. 1972. Insensitivity of the alveolar septum to local hypoxia. Am. J. Physiol. 223:770-776.

26. Gacad, G., and D. Massaro. 1973. Hyperoxia: influence on lung mechanics and protein synthesis. J. Clin. Invest. 52:559-565.

27. Block, E. R., and A. B. Fisher. 1977. Depression of serotonin clearance by rat lungs during oxygen exposure. J. Appl. Physiol. 42:33-38.

28. Clark, J. M., and C. J. Lambertsen. 1971. Pulmonary oxygen toxicity: a review. Pharmacol. Rev. 23:37-133. 